\section{AB0059 COMBINATION OF PLASMAPHERESIS AND INTRAVENOUS BOLUS ADMINISTRATION OF METHOTREXATE AND METHYLPREDNISOLONE IN REFRACTORY RHEUMATOID ARTHRITIS}

HA Asseeva, SK Soloviev, AS Chiklikchy. Of the Intensive Therapy, Institute of Rheumatology, Moscow, Russia

10.1136/annrheumdis-2001.1120

\section{Background}

Objectives To evaluate the effect of synchronic program of intensive therapy (SPIT) on patients with refractory RA.

Methods 20 RA patients with systemic manifestations: rheumatoid nodules (65\%), lymphadenopathia (45\%), fever (35\%), livedo vasculitis (10\%). 19 patients (95\%) demonstrated intorelability of inefficacy of previous basic therapy, 6 (30\%) had a corticosteroid dependency. Before the treatment Wilke?s Index activity was 7,06 , Index severity was $11,38.6$ courses of plasmapheresis synchronised with pulse-therapy of Methylprednisolone $(1500 \mathrm{mg})$ and Methotrexat $(240 \mathrm{mg})$ during 1 month, after that all patients were prescribed Methotrexat in dosage of 20 mg i.m. for 11 months.

Results 4 patients (20\%) had a clinico-laboratory remission in a year after beginning of treatment (Wilke,1993). In all group clinico-laboratory improvement was observed in a month and prolonged during the year. In all causes were no systemic manifestations in a month of the treatment. All 20 patients demonstrated the significant decrease of arthralgies, morning stiffness, number of inflamed joints, growth of indices of functional activity. Prednisolone was abolished in 2 patients and daily dosage was decreased in 4 patients/In a 6 months 16 patients $(80 \%)$ had a low clinico- laboratory activity. Side effects were minimal and were arrested without additional treatment.

Conclusion Synchronic program of intensive therapy can be considered the effective method of RA therapy enabling to achieve speedy clinical improvement, espessially during severe variants of the disease progressing with systemic manifestations, resistance to basic medication, corticosteroid dependency.

\section{AB0060 INTRAVENOUS PULSE OF METHOTREXATE AND METHYLPREDNISOLONE/DEXAMETHASONE IN THE TREATMENT OF SEVERE RHEUMATOID ARTHRITIS}

SK Soloviev, NY Nykishina, EA Asseeva. Of the Intensive Therapy, Institute of Rheumatology, Moscow, Russia

\subsection{6/annrheumdis-2001.1121}

\section{Background}

Objectives To assess the effect of combination of high doses of Methotrexate and Pulse-therapy of corticosteroids in 12 months $\phi$ trial.

Methods Thirty one patients with systemic rheumatoid arthritis, resistance to basic medication, corticosteroid dependency were included into the study. Intravenous (i.v) pulse-therapy was provided for 3 days by methylprednisolone of $15 / \mathrm{mg} / \mathrm{kg} / \mathrm{d}$ or dexamethasone of $2 / \mathrm{mg} / \mathrm{kg} / \mathrm{d}$. Methotrexate of $100 \mathrm{mg}$ i.v. was administrated on 7 and 30 days of the treatment, after that all patients were prescribed Methotrexat in dosage of $20 \mathrm{mg}$ i.m. for 11 months.

Results Clinical effects of treatment and the regression of inflammatory activity were rapid and excellent in 1 month and prolonged during $6 \square 12$ months. There was $20 \%$ improvement in the joint pain index and joint swelling index in $>95 \%, 45 \%$,
$65 \%$ of the patients in a $1,6,12$ months therapy respectively. In a year was observed the significant decrease of Wilke?s Index activity and Index severity. There were a marked fall in ESR, CRP and TNF. 12 pts had no radiographic progression in one year therapy. Side effects were minimal, In $43 \%$ causes were observed dyspepsia.

Conclusion Intravenous pulse of methotrexate and methylprednisolone/dexamethasone in the treatment of severe rheumatoid arthritis appeared to be useful regimen in the treatment of rheumatoid arthritis with systemic manifestations, resistance to basic medication, corticosteroid dependency.

\section{AB0061 CIRCULATING ADENOSINE LEVELS AFTER INITIATION OF METHOTREXATE AND ANTI-TNF THERAPY IN RA}

P Barrera, AE Van Ede, M Creemers, RF Laan, RA De Abreu, LB Van de Putte. Rheumatology, University Medical Center Nijmegen, Nijmegen, The Netherlands

\subsection{6/annrheumdis-2001.1122}

Background Adenosine exerts strong anti-inflammatory effects.

In vitro and animal studies suggest that adenosine release is implicated in the mechanism of action of methotrexate (MTX) and sulfasalazine. Whether blocking TNF has any effect on this pathway has not been investigated yet.

Objectives To assess the short anf mid-term effect of MTX and anti-TNF therapy on the circulating levels of adenosine and aminoimidazolcarboximide ribotide (AICAR) in rheumatoid arthritis (RA).

Methods Patients starting therapy with MTX ( $\mathrm{n}=10$; dose 15 $\mathrm{mg} / \mathrm{kg} \mathrm{im}$ ) or infliximab ( $\mathrm{n}=10$, dose $3 \mathrm{mg} / \mathrm{kg}$ ) were enrolled in the study. Blood samples were drawn immediately before and 2, 6, 24 and $48 \mathrm{~h}$ and 4 weeks after the first administration of MTX or anti-TNF. Measurements before and 2 and $6 \mathrm{~h}$ after administration were also performed on week 12 . To avoid adenosine degradation, blood was directly mixed with a solution containing EHNA $10 \mu \mathrm{M}$, dipyridamole $20 \mu \mathrm{M}$ and indomethacin $2 \mathrm{mg} / \mathrm{L}$. Adenosine and AICAR were measured using sensitive HPLC methods. Response to therapy was assessed at week 4 and 12 using the EULAR criteria.

Results Baseline adenosine levels were similar in both patient groups (median, [p25 - p75] 213 [146 - 302] and 230 [71 291] $\mathrm{nmol} / \mathrm{L}$ for MTX and anti-TNF respectively). Adenosine levels showed marked inter- and intra-individual variability $(75 \%$ and $49 \%$ respectively). In 3 patients, adenosine concentrations raised markedly $2 \mathrm{~h}$ after the first MTX dose. Nevertheless, no consistent changes were observed in the whole MTX group or after anti-TNF administration.

Within the study period, $55 \%$ and $64 \%$ of the patients receiving MTX and anti-TNF showed clinical response. The latter was also not reflected in the levels of adenosine. AICAR could not be detected in any of the samples.

Conclusion In patients with RA, neither MTX therapy nor its effectivity are mirrored by consistent changes in circulating adenosine levels. The same holds true for anti-TNF treatment. This does not exclude the possibility of a modulation of adenosine release at the target organ. 